\title{
Do Investors Herd: Evidence from an Emerging Market
}

\section{Safi Ullah Khan* and Muhammad Faisal Rizwan ${ }^{* *}$}

\begin{abstract}
Employing stock price data from a developing market, we examine whether investors' trading patterns are characterized as herd behavior at the market and industry levels. Unlike results for some developing markets, linear models of herd behavior find no evidence of herd formation, in any of the sectors, during periods of large market movements. However, non-linear models find significant nonlinear herding behavior only for two sectors of the whole sample, and when we group the sub-samples based on up and down market movements. Overall, empirical results tend to support the notion of no herd formation in Pakistan's market. Two main explanations may be offered for the results: first, a developing market, characterized by thin trading and low turnover, with few of the stocks from various sectors actively traded in the market. Second, individual investors that dominate Pakistan's equity market and low levels of institutional investor's presence preclude herd formations.
\end{abstract}

Keywords: Herd behavior, herding, institutional investors, cross-sectional standard deviation of returns

JEL classifications: G11, G12.

\section{Introduction}

The phenomenon of humans tending to mimic the behavior and actions of others has been observed in a variety of social and economic environments. This imitative and correlated behavior in financial markets, , referred to as herding by Nofsinger and Sias (1999), results in investor groups trading in the same direction over time. This tendency of investors to imitate the observed behavior of fellow investors carries an important implication for financial markets as herding implies that investors may be suppressing their private information (Hwang and Salmon, 2004). This can cause stock prices to deviate from their fundamental value. By contrast,

\footnotetext{
${ }^{*}$ Senior Assistant Professor, Universiti Teknologi Brunei, Brunei Darussalam.

** Assistant Professor, Faculty of Management Science, International Islamic University Islamabad, Pakistan.
} 
herding can be rational, as with information-based herding (Welch, 1992)1, or it can be rational in a "utility maximizing" sense, with the thinking that better informed participants in the market move away from the market consensus which can be costly in terms of reputation (Scharfstein and Stein, 1990) or loss of compensation (Roll, 1992).

Herding in financial markets is well-documented. Previous studies have predominantly focused on the investment behavior of institutional investors, mainly pension funds (Voronkova and Bohl, 2005; Badrinath and Wahal, 2002; Kremer and Nautz, 2011), fund managers (Liao, Huang, and $\mathrm{Wu}, 2011$ ), mutual funds (Walter and Weber, 2006; Grinblat, Titman and Wermers, 1995) or foreign institutional investors (Shyu and Sun, 2010). This growing interest in the institutional investors' behavior is partly stimulated by their relative growing dominance in financial markets worldwide (Nofsinger and Sias, 1999), the possible influence of their trading patterns on asset prices, and, partly, the common perception that institutional investors engage more in herding and feedback trading than individual investors. Their actions may contribute to the destabilization of capital markets, diluting the information quality of prices and aggravating stock price volatility (Walter and Weber, 201006 Voronkova and Bohl, 2005). Nevertheless, some researchers (Natividad, Pilar and Sandra, 2011) argue that institutional investors are expected to be well-equipped, better informed (Li, Rhee and Wang, 2009), and have superior capabilities to better interpret the information as compared to other market participants so may not have incentive to engage in intentional herd behavior. Thus, studies on institutional herding find diverse results (Grinblatt, Titman and Wermers, 1995; Wermers, 1999; Li and Yung, 2004; Liao et al., 2011; Holmes, Kallinterakis and Ferreira, 2011). Hence, results from studies on the behavior of institutional investors has little relevance for individual investors. This necessitates the need to focus on the behavior of the individual retail investors in markets dominated by domestic individual investors. This study attempts to fill this gap by examining a developing market like Pakistan.

This study examines whether herding behavior exists at the overall market level and at the industry level. We know little about individual investment behavior in relation to the presence of herding in developing financial markets. This paper extends the literature to an emerging

\footnotetext{
${ }^{1}$ In this case, independent and informed investors such as institutional investors, take actions spurred by the movements in fundamentals. Bikhchandani and Sharma (2001) call this type of herding as "spurious" or "unintentional herding".
} 
market-that dominated by individual retail investors, as compared to foreign or institutional investors.

Our study contributes to the literature on equity investors' herding behavior in several ways. There is limited and mixed evidence on herd behavior in emerging markets, and those studies are restricted only to a few markets, such as Taiwan, Hong Kong, South Korea, and few Latin American markets. The current study extends this literature to Pakistan's market in two distinct aspects namely, (i) market-wide and sector-specific evidence of herd behavior, and (ii) herd behavior within the same market, accounting for the thin trading phenomenon as a robustness check. Previous studies on Pakistan's market have not accounted for this anomaly. Although Javed et al., (2013), Shah et al. (2017), Javaira and Hassan (2015), Yousaf et al. (2018) examine herd behavior for Pakistan's market, our paper differs from these studies since we account for the phenomenon of thin trading. This helps to avoid confounding results with herding and thin trading. Finally, we use a sufficiently large sample interval to minimize the influence of any bias produced by any market effects.

The rest of the paper is organized as follows. Second section reviews relevant literature, followed by methodology and analysis, and the last section concludes the paper.

\section{Literature Overview}

Empirical examinations of herding in financial markets have been conducted along two distinct lines. The first line of research, pioneered by Christie and Hwang (1995), examines herd behavior based on the crosssectional dispersion of stock returns in different extreme market conditions. In this model, Cross-Sectional Standard Deviation (CSSD) is regressed against two dummies that represent extreme positive and extreme negative returns. Chang et al. (2000) modified Christie and Hwang's model by using the absolute measure of CSSD to examine herding for the U.S. and some Asian markets. Christie and Hwang's model is based on the notion that, during normal market conditions, each asset will react to the aggregate changes in the market in its own specific way depending on its sensitivity to those changes, so we should observe substantial variation in CSSD of returns. When market participants are engaged in herd behavior individual stock returns tend to deviate little from the overall aggregate market returns. The resulting lower CSSDs in individual security returns is a sign of the presence of herd behavior. Hence, herd behavior and asset pricing models tend to differ in their 
predictions of the behavior of stock return dispersion, particularly during market stress. These models have been applied in different markets, mainly during conditions of market stress, and for both institutional and individual investors. The evidence for herd behavior has predominantly been found in developing markets as compared to developed markets. For instance, Chang et al. (2000) report that investors in the U.S. and Hong Kong markets do not herd, while those of South Korea and Taiwan do herd significantly. Gleason et al. (2004) used Christie and Hwang's model for Exchange Traded Funds (ETFs) and find no evidence of herd behavior either during extreme up or extreme down market movements for ETFs. Demirer and Kutan (2006) have found no evidence of herd behavior for the Chinese market using firm- and sector-level data, during periods of extreme up and down markets. Conversely, Dorn, Hubberman, and Psengmuller (2003) found strong evidence of herd behavior for German retail investors at a German broker using daily and quarterly intervals.

Li, Rhee, and Wang (2009) document more intense herding by better-informed institutional investors as compared to individual investors. Nevertheless, their paper also documents the tendency for lessinformed individual trader's to rely on public information and, consequently, their vulnerability to the influences of market sentiments and popular eye-catching events. Chiang and Zhen (2010) examine herding behavior in 18 countries using Christie and Hwang's model and have found evidence of herding behavior in Asian markets, but no evidence of herding in U.S. and Latin American markets. This herd behavior was found during both up and down markets, though the intensity was more pronounced for Asian markets, particularly during up markets.

In addition to Christie and Hwang's model, there is another model that has found widespread application in the literature on herd behavior, developed by Hwang and Salmon (2004). Though the spirit of this model is similar to that of Christie and Hwang, it is based on the CSSD of the factor sensitivity of assets, instead of the returns. This enables the model to avoid the influence of idiosyncratic components. Hwang and Salmon (2004) suggest that when investors herd, normal risk-return equilibrium in the conventional Capital Asset Pricing Model (CAPM) is disturbed which causes betas of the assets to move away from equilibrium, resulting in the CSSD to be smaller than what it would have been in equilibrium. Hwang and Salmon explain this bias in individual betas as a shift in beliefs which occurs because investors follow the sentiments of the market. Applying their model to the U.S. and South Korean equity markets, Hwang and Salmon found that herd behavior shows significant variation and 
persistence over time, independent of given market conditions and macroeconomic factors, as these factors failed to explain any variations in the herding. Other studies that have used Hwang and Salmon's model include Demirer, Kutan, and Chen (2007) for Taiwanese firm-level data and have documented strong evidence of herding in all sectors of that market. Wang (2008) document higher levels of herd behavior for several emerging markets in Asia using Hwang and Salmon's model and FamaFrench's three-factor model. Recently, Kallinterakis (2009) has extended the model to the Vietnam market and adjusts returns for thin trading-a feature of emerging markets. They found that adjustment for thin trading depresses herding significance in the market.

In summary, regardless of which model studies have used, results for the presence of herd behavior in different markets are mixed, and at times, elusive. Empirical evidence of the presence of herding in financial markets, however, tilts more towards developing markets.

\section{Data and Methodology}

We employed two empirical models in this study to evaluate herd behavior at the market-wide and industry-wide levels. These models are based on the Cross-Sectional Standard Deviation (CSSD) model of stock returns. Christie and Huang (1995) proposed this model to empirically identify herd behavior at the market-wide level by utilizing crosssectional data on stock returns. Christie and Huang define CSSD by the following equation:

$$
\operatorname{CSSD}_{t}=\sqrt{\frac{\sum_{i=1}^{n}\left(r_{i, t}-r_{p, t}\right)^{2}}{n-1}}
$$

where $n$ is the number of stocks in the portfolio and $r_{i, t}\left(r_{p, t}\right)$ is the realized individual security (equally-weighted portfolio) returns for day $t$.

The rationale behind this measure is that, in the presence of herd behavior, individual asset returns will move in tandem with overall market returns as investors suppress their own private information (opinion) and make investment decisions by following collective market actions. This would lead the CSSD among stocks to be lower than the usual dispersion and would be indicative of the presence of herd behavior

Christie and Huang's model also assumes that the tendency of investors to herd will be higher during extreme market movements, as they 
will most likely suppress their opinion in favor of market consensus during such market conditions. Traditional asset pricing models and literature on herd behavior in financial markets have different predictions for the crosssectional variations in asset returns. Classical asset pricing models predict that this cross-sectional variation will be higher during market stress because of the different sensitivities of assets to aggregate market changes. In contrast, market-wide herding behavior suggests that the dispersion will be lower during large market movements as there is a higher tendency that investors will be swept along with the collective market behavior. Hence, we also test for the presence of market herding during large market movements through the following equation of Christie and Huang's model.

$$
\operatorname{CSSD}_{t}=\propto+\gamma^{L} D_{t}^{L}+\gamma^{U} D_{t}^{U}+\varepsilon_{t}
$$

where $D_{t}^{L}\left(D_{t}^{U}\right)$ is a dummy variable that is equal to market returns on a day $t$ fall in the extreme lower (upper) boundary of the returns distributions ${ }^{2}$. $\operatorname{CSSD}_{t}$ represents cross-sectional dispersion of variations in asset returns as defined by equation (1) and $\propto$ represents mean dispersion for the sample, not including the days represented by the two dummies. Thus, the two dummies capture differential return dispersion between extreme up or down market movements and the normal market movements. Statistically significant negative (positive) coefficients for the two dummies will be indicative of the presence (absence) of herd behavior in the market during extreme up or down markets.

\subsection{Asymmetric Behavior of Herding and herding under different market conditions}

To avoid the possibility that the $C S S D_{t}$ measure is sensitive to outliers since it is measured as squared return-deviations, Chang et al. (2000) proposed an alternative model by incorporating the absolute value of the deviations and define Cross-sectional Absolute Deviation (CSAD) as a measure of return dispersion, described by the following specification:

$$
\operatorname{CSAD}_{t}=\frac{1}{N} \sum_{i=1}^{N}\left|r_{i, t}-r_{m, t}\right|
$$

Chang et al. (2000) built their model on the theoretical intuition that the linear relationship between CSAD and market returns, as suggested by asset pricing models (CAPM), may not necessarily hold during periods of

\footnotetext{
${ }^{2}$ Christie and Huang have used 1 (5) percent of observations in lower (upper) tail of the return distributions to define extreme up (down) market
} 
market stress if investors tend to herd during extreme market movements. Instead, the relationship can become non-linear. Chang et al. models this non-linear relationship by the following equation:

$$
C S A D_{t}=\propto+\gamma_{1}\left|r_{m, t}\right|+\gamma_{2} r_{m, t}^{2}+\varepsilon_{t}
$$

where $r_{m, t}$ is the realized return on an equally-weighted portfolio of all stocks on day $\mathrm{t}$ and $\left|r_{m, t}\right|$ is the absolute term. If investors herd during periods of large price movements we would expect a negative and statistically significant non-linear coefficient $\left(\gamma_{2}\right)$ that implies that the dispersion between individual returns and market returns will decline non-linearly during large market movements. Alternatively, a statistically significant positive $\gamma_{2}$ would indicate that there would be no evidence of herding during market stress.

To be more specific and comprehensive in our analysis, and allow for the possibility of an asymmetric relationship of herd behavior for upmarket in comparison to the days when the market was down, we ran the following two additional equations of Chang et al. (2000) model:

$$
\begin{aligned}
& C S A D_{t}^{U P}=\propto+\gamma_{1}^{U P}\left|r_{m, t}^{U P}\right|+\gamma_{2}^{U P}\left(r_{m, t}^{U P}\right)^{2}+\varepsilon_{t} \\
& C S A D_{t}^{D O W N}=\propto+\gamma_{1}^{D O W N}\left|r_{m, t}^{D O W N}\right|+\gamma_{2}^{D O W N}\left(r_{m, t}^{D O W N}\right)^{2}+\varepsilon_{t}
\end{aligned}
$$

where $r_{m, t}$ represents returns on an equally-weighted market portfolio and $\left|r_{m, t}^{U P}\right|\left(\left|r_{m, t}^{D O W N}\right|\right)$ is the up (down) realized market returns on the equallyweighted portfolio on day $t$. The up (down) market returns are defined as positive (negative) returns on a day $t$ (Chang et al., 2000).

\subsection{Herding and Thin Trading}

One of the features of emerging markets is the infrequent (thin) and non-synchronous trading that occurs when infrequently traded stocks have long sequences of zero returns which can induce false autocorrelations in the returns series. This can introduce bias in empirical estimations, particularly in relation to market efficiency estimates, as shown by studies of Lo and Mackinlay (1990), Miller et al. (1994), and Antoniou et al. (1997). Kallinterakis and Kratunova (2007) showed that thin trading could underestimate the intensity of herd behavior in a thinly traded market. Utilizing top capitalization stocks data from the Bulgarian market SFIX index, the authors found insignificant herding estimations prior to thin trading adjustments to the data, whereas post-adjustments 
showed increasing signs of significant herd formations. The authors attributed this to the illiquidity of the market and suggested illiquidity as an obstacle to herding by market participants. Kallinterakis (2009) studied the Vietnam market and also suggests thin trading to have a positive bias over herding. In such a case, we could expect thin trading to have an effect on herding estimations in a developing market like Pakistan.

To account for thin trading, we employed the methodology of Miller et al. (1994) which shows that returns can be adjusted for thin trading through an adjusted returns (AR) (1) process:

$$
R_{t}=\propto_{1}+\propto_{2} R_{t-1}+\varepsilon_{t}
$$

Adjusted returns are then obtained as:

$$
R_{t}^{a d j}=\frac{\varepsilon_{t}}{\left(1-\varepsilon_{t}\right)}
$$

A problem with equation (8) is that it assumes adjustments to be time-invariant, which may not hold true for emerging markets where windows of trading inertia often exist (Kallinterakis, 2009). As an alternative, Antonio et al. (1997) suggested a recursive estimation of the equation (8) which we also adopted in this study given the very possibility of thin trading in Pakistan's market.

\subsection{Data}

We used daily stock price data and year-end market capitalization returns data for 284 firms traded on the Pakistan Stock Exchange from 1 January 2002 to 31 December 2010 to examine herding in Pakistan's market. The daily stock prices and market capitalization data for these firms were collected from an online database maintained by Business Recorder, a premier daily business newspaper in Pakistan. The sample time period covers various extreme up and down market movements, including the March 2005 crisis and bear market period of 2008, as well as the bull market period from 2002 to early 2005.

Prior studies on herd behavior in financial markets are based on a rationale that a group is more likely to be involved in herd behavior if it is sufficiently homogenous. Consequently, empirical studies (Christie and Huang, 1995; Henker, Henker and Mitsios, 2006; Demirer et al., 2007; Chiang and Zheng, 2010) have conducted herding tests on groups (or sectors) of stocks. In line with previous studies, we assigned 284 stocks to 18 sectorial 
groups in our sample. An equally-weighted portfolio return for each sector was then calculated for all stocks in that sector. We use Karachi Stock Exchange (KSE) 100 Index to proxy for market returns. KSE-100 Index is a value-weighted index of 100 companies selected from all sectors of the economy based on the market capitalization. It represents more than 80 percent of the market capitalization and is a fair representation of the market.

\subsection{Empirical Results}

Summary descriptive statistics for mean daily log returns (Panel A) and Cross-Sectional Standard Deviation (CSSD) 3 for various sectors are reported in Table 1. As panel A of the table shows that average returns for all except three sectors (power generation and distribution, synthetic and rayon, and banks) are positive, while power generation and distribution, and synthetic and rayon have highest daily mean returns volatility. Panel $B$ reports univariate statistics for the measure of cross-sectional return dispersion (CSSD) for each sector. The table shows that technology and communications has the highest CSSD, followed by synthetic and rayon, while the fertilizer sector displays the lowest level of dispersion. Comparing maximum and minimum values of the daily CSSD indicates that the technology and communications sector has the highest value, while the fertilizer sector has the lowest maximum value. A number of sectors have a minimum value of zero for CSSD suggesting that on those days there was no trading in any of the stocks in a particular sector. Table 1 also reports autocorrelation values at different lags for the CSSD series. It is evident from the table that the time series of CSSD for all sectors appears to have high autocorrelations. The first-order autocorrelation has a maximum value of 0.339 for technology and communications and lowest value of 0.130 for Vanaspati and Allied. Hence, we adjusted standard errors of the estimated regression coefficients for autocorrelations and heteroscedasticity by employing an approach attributed to Newey and West (1987). Further, it is evident from the table that CSSD for all sectors exhibits significant positive skew and kurtosis. Dickey and Fuller (1979) test indicated that the series is stationary for all sectors.

\footnotetext{
${ }^{3}$ We also calculated descriptive summary statistics for CSAD. The mean and standard deviation values for majority of the sectors were higher than that of CSSD
} 
Table 1. Descriptive Statistics Panel A: Average Daily Rates of Returns

\begin{tabular}{lcc}
\hline Sector & Mean & Std. Dev. \\
\hline Chemicals & 0.0486 & 1.5449 \\
Engineering & 0.0803 & 1.4726 \\
Glass and Ceramics & 0.0085 & 1.8822 \\
Paper and Board & 0.0114 & 1.5324 \\
Pharmaceuticals & 0.0532 & 1.0949 \\
Power Generation and Distribution & -0.0047 & 2.3557 \\
Refinery & 0.0016 & 2.1425 \\
Sugar and Allied Industries & 0.0439 & 1.6492 \\
Synthetic and Rayon & -0.0487 & 3.1384 \\
Technology and Communication & -0.0130 & 2.1803 \\
Vanaspati and Allied Industries & 0.0642 & 1.9047 \\
Woolen & 0.1148 & 1.7179 \\
Cement & 0.0136 & 2.1863 \\
Fertilizer & 0.0327 & 1.7047 \\
Oil and Gas Exploration Companies & 0.0478 & 2.1142 \\
Oil and Gas Marketing & 0.0172 & 1.7596 \\
Commercial Banks & -0.0189 & 1.9060 \\
Automobiles Assembler & 0.0104 & 1.5825 \\
\hline
\end{tabular}

This panel provides mean and standard deviation of daily stock returns for 18 sectors. 


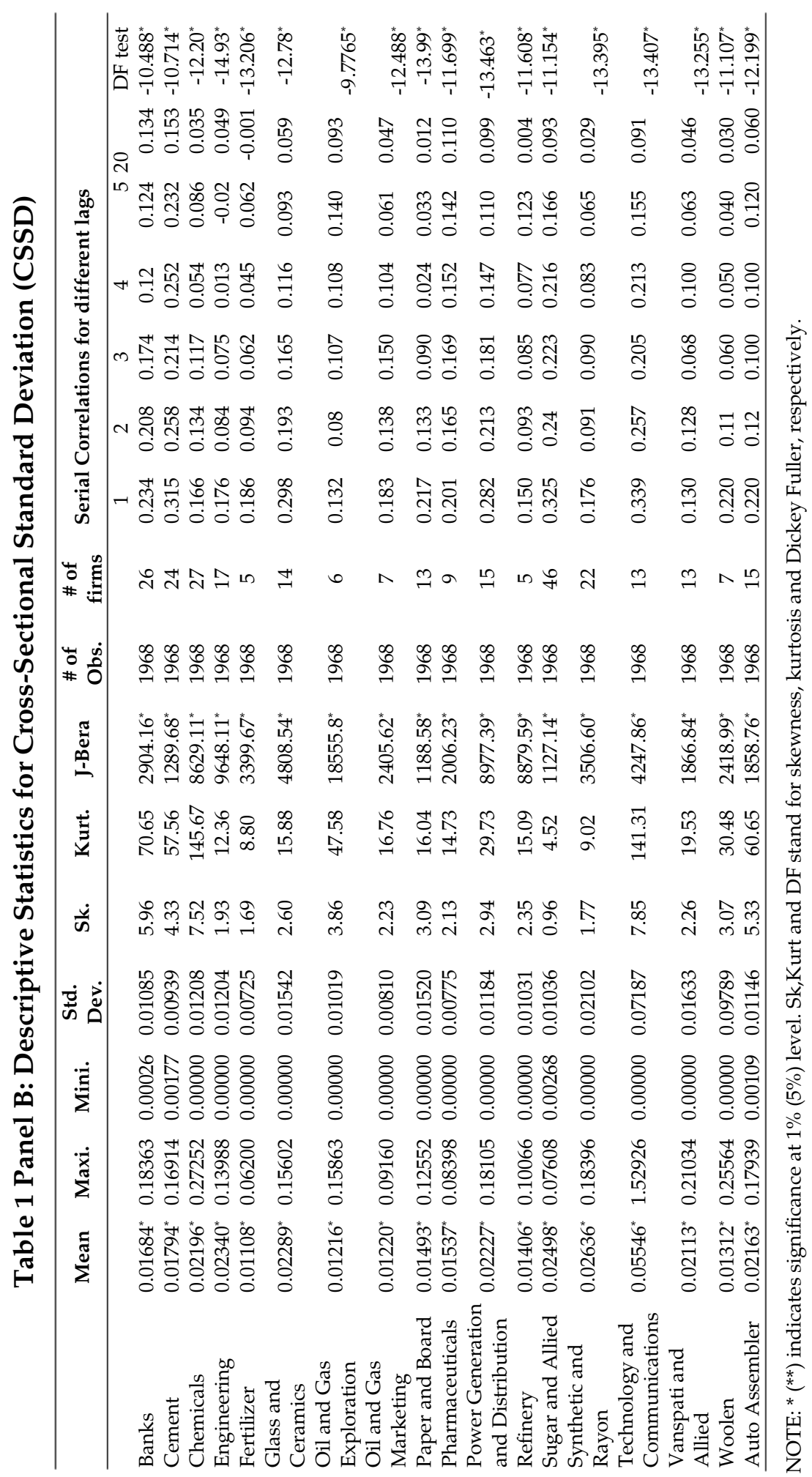




\subsubsection{Evidence of Herd Behavior: Returns Dispersion Model}

Results of the dispersion model (equation 2) are reported in Table 2. We used daily returns of KSE-100 Index as a proxy for market returns and used the upper and lower 5 percentiles of the index returns as periods of large price movements, termed as market stress. As shown by Table 2, positive and significant dummy variable coefficients indicate that we did not find any evidence of herd behavior in any of the sectors, during large price movements. Positive dummy coefficients $\left(B^{L}\right.$ and $\left.B^{D}\right)$ also imply that equity return dispersions tend to increase during periods of large price movements in the market. These findings are not consistent with our definition of herding in which case we would have observed a decrease in equity dispersion levels.

Table 2: Regression analysis Cross-Sectional Standard Deviation (CSSD)

\begin{tabular}{lccccc}
\hline Industry & $\boldsymbol{\alpha}$ & $\gamma^{U}$ & $\boldsymbol{\gamma}^{\boldsymbol{L}}$ & $\mathbf{A d j} . \mathbf{R}^{2}$ & F-test \\
\hline Cement & $0.0179^{*}$ & $0.0229^{*}$ & $0.1603^{*}$ & 0.029 & $7.36^{*}$ \\
Fertilizer & $0.0115^{*}$ & $0.0011^{*}$ & $0.0187^{*}$ & 0.048 & $20.59^{*}$ \\
Oil and Gas Exploration & $0.0111^{*}$ & $0.1016^{*}$ & $-0.0078^{* *}$ & 0.039 & $9.86^{*}$ \\
Oil and Gas Marketing & $0.0117^{*}$ & $0.0010^{*}$ & $0.0251^{*}$ & 0.044 & $20.67^{*}$ \\
Commercial Banks & $0.0192^{*}$ & 0.0005 & $0.0897^{*}$ & 0.054 & $25.87^{*}$ \\
Automobiles Assembler & $0.0167^{*}$ & $0.0135^{*}$ & $0.0379^{*}$ & 0.050 & $20.65^{*}$ \\
Engineering & $0.0281^{*}$ & $0.0073^{*}$ & 0.0006 & 0.028 & $12.89^{*}$ \\
Glass and Ceramics & $0.0216^{*}$ & 0.0063 & 0.0022 & 0.080 & $51.34^{*}$ \\
Paper and Board & $0.0215^{*}$ & 0.0027 & $-0.0029^{*}$ & 0.038 & $17.83^{*}$ \\
Pharmaceuticals & $0.0173^{*}$ & 0.0003 & $0.0013^{*}$ & 0.029 & $13.89^{*}$ \\
Refinery & $0.0144^{*}$ & $0.0042^{*}$ & -0.0004 & 0.048 & $22.83^{*}$ \\
Sugar and Allied & $0.0279^{*}$ & 0.0011 & -0.0008 & 0.078 & $37.22^{*}$ \\
Synthetic and Rayon & $0.0351^{*}$ & $0.0133^{*}$ & 0.0024 & 0.042 & $19.96^{*}$ \\
Technology and Communication & $0.0216^{*}$ & 0.0039 & -0.0002 & 0.028 & $8.49^{*}$ \\
Vanaspati and Allied Industries & $0.0239^{*}$ & 0.0008 & -0.0006 & 0.027 & $7.59^{*}$ \\
Woolen & $1.1066^{*}$ & -0.3905 & -0.0610 & 0.032 & $6.89^{*}$ \\
Chemicals & $0.0279^{*}$ & $0.0095^{*}$ & 0.0009 & 0.019 & $5.59^{*}$ \\
Power Generation and & 0.0388 & 0.0156 & 0.1827 & 0.001 & 1.78 \\
Distribution & & & & & \\
\hline
\end{tabular}

This table provides results for the Christie and Huang model (equation 2) to detect herd behavior at the market and industry level. Separate regressions were done for each of the 18 sectors. $\gamma^{U}\left(\gamma^{L}\right)$ is a coefficient for dummy variable that is equal to one if the market returns on a day $t$ fall in the extreme lower (upper) boundary of the returns distributions. * $\left.{ }^{* *}\right)$ represent significance at the $1(5)$ percent level, respectively.

Table 3 reports results for the Chang et al. (2000) model of equations: (4), (5), and (6). We followed the standard procedure of the model by running three separate regressions for each sector, one using data from the entire sample and one regression each for the periods of up and down 
market movements ${ }^{4}$. This procedure allowed us to account for any significant non-linear asymmetric effects in the herd behavior. First, we examined coefficient results of the model for the entire sample period. The mean value of the equity dispersions, as measured by the regression coefficient $\alpha$, has the highest value for the technology and communication sector and the lowest value for the fertilizer sector. Furthermore, the table shows that $\gamma_{1}$ coefficient for all sectors for the linear term $\left|R_{m t}\right|$ are positive and statistically different from zero ${ }^{5}$ for the model (entire sample). These results imply that CSAD tends to increase with $\left|R_{m t}\right|$. Next, we considered the linear term coefficient $\left(\gamma_{1}\right)$ for the two sub-periods. $\gamma_{1}$ for periods of up and down market movements are also positive and statistically significant for the majority of the sectors. This implies that equity return dispersions also tend to increase with market movements irrespective of the direction of the market. We cannot, however, differentiate as a whole, whether the increase in equity dispersion is higher (on the basis of the values of $\gamma_{1}$ ) for either up or down market movements as, for some sectors, this increase is higher for up market movements, but for other sectors this increase is higher for down market movements. In other words, it does not suggest that the dispersions are, on average, wider for up or down market movements.

${ }^{4} \mathrm{Up}$ (Down) market is defined as one when the index returns are positive (negative) on a day t. ${ }^{5}$ Coefficients for three sectors are negative but not statistically significant. 


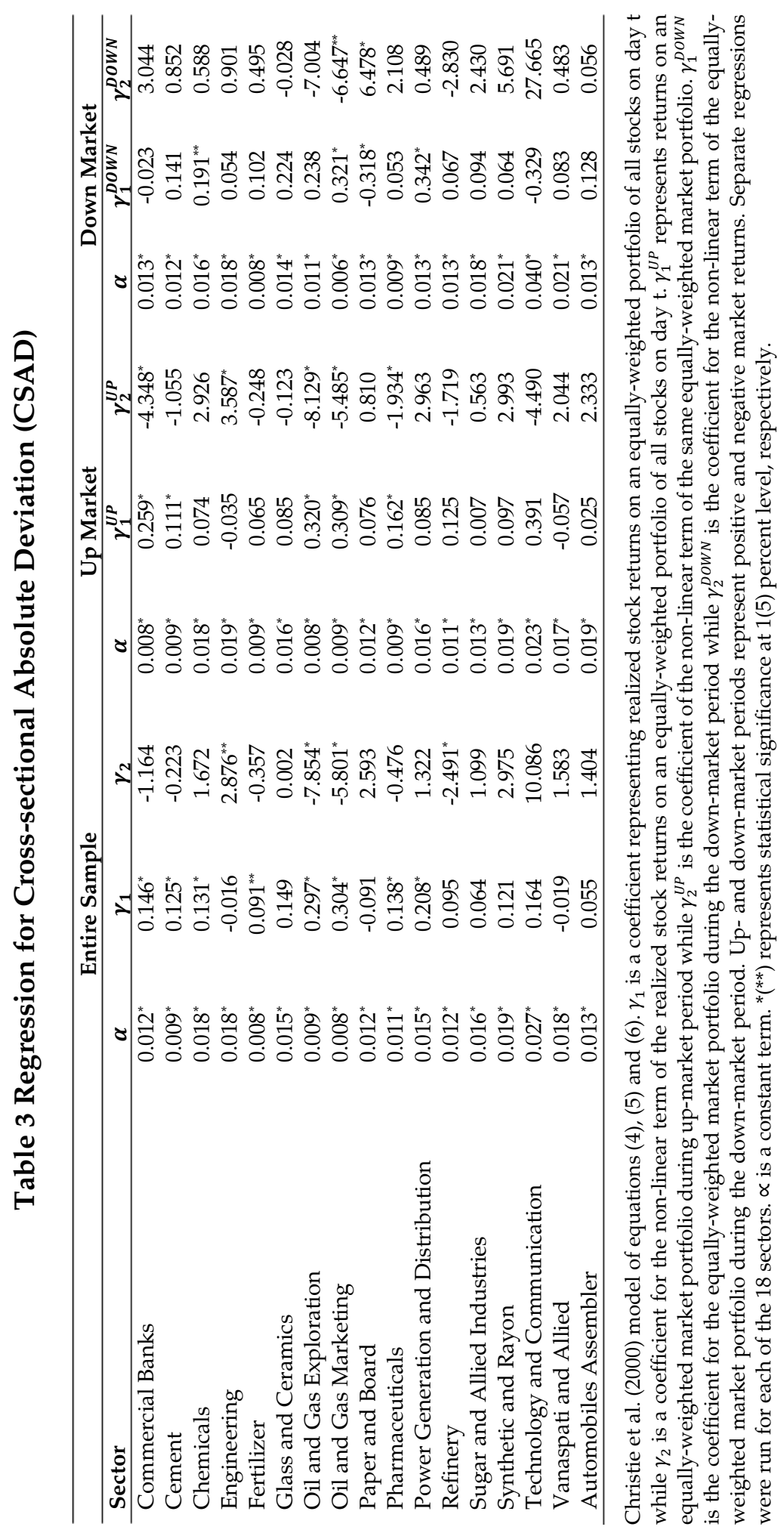


We then examined results for the non-linear coefficient $\left(\gamma^{2}\right)$. This coefficient is not statistically significant for all except three sectors for the two sample intervals, namely the entire sample data and the up market period. This statistically insignificant $\gamma^{2}$ supports predictions of the rational asset pricing models and is consistent with the results of Table 2, that is, a positive linear relationship of CSAD with market returns and the absence of herd formations in the majority of the sectors. These results imply that as the average market returns increase, the CSAD in the two sectors increases at a decreasing rate-a sign of the absence of herd formation. The negative $\gamma^{2}$ also implies that CSAD increases at a decreasing rate as investors suppress private information in favor of the sector consensus. The only exceptions to these results are the three sectors of oil and gas marketing, oil and gas exploration, and pharmaceuticals, for which $\gamma^{\wedge} 2$ for the entire sample as well as up market periods are negative and statistically significant. A positive and linear relationship between equity dispersion and market returns does not hold for these sectors. Several plausible explanations could be offered for the occurrence of herding formations in these two inter-related sectors. First, most of the stocks in the oil and gas exploration sector are considered as cash-rich stocks. Trading activity in such stocks tends to be higher than the other stocks. This may cause the prices of these shares to move in tandem with the market movements. Additionally, foreign investors are mainly concentrated in this sector and hold a large portion of their investment portfolio in the sector ${ }^{6}$. Several studies find that foreign institutional investors engage more in herding and feedback trading than the domestic individual investors (Wermers, 1999; and Shyu and Sun, 2010). Foreign portfolio investment flows have the potential to destabilize the market in the host country because they are short-term flows (Tayde and Roa, 2011). This might result in the presence of herd formation in these two sectors.

When we examined regressions run separately for up and down market returns, we did not find any difference in the patterns of equity return dispersions for the two market movements. Similar to the data for the entire sample, evidence of herd formation is not found for any of the sectors, except for two during up market movements, and for only one sector during down market movements.

As a robustness check, we also accounted for the phenomenon of thin trading by employing recursive estimation of equation (8). Results, not

\footnotetext{
${ }^{6}$ Bava (2012) estimates that almost $50 \%$ of the portfolio of foreign investors are concentrated in oil and gas sector
} 
reported here, remain qualitatively similar to those reported in Table 3. Overall, empirical results tend to support the notion of no herd formation in Pakistan's market. These results are not in line with many of the findings for developing markets, where although the evidence is mixed with some studies finding the presence of herd behavior in many developing markets, some studies find no such evidence in other markets. However, the balance of the evidence tilts towards herd formations in developing markets as compared to industrialized markets. Several explanations may be offered for the results for Pakistan's market. First, being a developing market, Pakistan's is characterized by thin trading and low turnover. Many of the stocks in various sectors are not actively traded. Second, Pakistan's market is mainly dominated by small investors with little presence of institutional investors.

\section{Conclusion}

There is a growing body of literature in behavioral finance on the study of herd behavior in financial markets, particularly in emerging markets. In this paper, we extended models of herd behavior to an emerging market by employing firm-level data for 18 sectors in Pakistan's market. Two models of herding were used in the study. The linear model of Christie and Huang (1995) finds no evidence of herd formation, in any of the sectors, during periods of large market movements. Similarly, nonlinear model of Chang et al. (2000) also finds no evidence for herd behavior for all but two sectors for the whole sample and for sub-samples upward and downward market movements. Overall, results predominantly support the view that there is little herd formation in Pakistan's market. Further, the phenomenon of thin trading is typical of many markets and incorporating such market frictions in future studies can help generalize the results and arrive at conclusions that are more robust. 


\section{References}

Antoniou, A., Ergul, N., Holmes, P., \& Priestley, R. (1997). Technical analysis, trading volume and market efficiency: Evidence from an emerging market. Applied Financial Economics, 7, 361-365.

Bava, A. (2012). Identifying safe bets. The News, p-21

Badrinath, S.G., \& Wahal, S. (2002). Momentum trading by institutions. The Journal of Finance, 57, 2449-78.

Bikhchandani, S., \& Sharma, S. (2001). Herd behavior in financial markets, IMF Staff Papers, WP/0048

Chang, E.C., Cheng, J.W., \& Khorana, A. (2000). An examination of herd behavior in equity markets: An international perspective. Journal of Banking and Finance, 24, 1651-79.

Chiang, T., \& Zheng, D. (2010). An empirical analysis of herd behavior in global stock markets. Journal of Banking and Finance, 34, 1911-21.

Christie, W.G., \& Huang, R.D. (1995). Following the pied piper: Do individual returns herd around the market? Financial Analysts Journal, 51, 31-37.

Christie, W.G., \& Huang, R.D. (1995). Relative performance measurement: the information in equity returns dispersions. Working paper, Owen Graduate School of Management, Nashville, TN.

Demirer, R., \& Kutan, A. (2006). Does herding behavior exist in Chinese stock markets? Journal of International Financial Markets, Institutions and Money, 16(2), 123-142.

Demirer, R., Kutan, A.M., \& Chen, C.D. (2007). Do investors herd in emerging stock markets? Evidence from the Taiwanese market. Journal of Economic Behavior and Organization, 76(2), 555-583.

Dickey, D. A., \& Fuller, W. A. (1979). Distribution of the estimators for autoregressive time series with a unit root. Journal of the American Statistical Association, 74(366), 427-431. 
Dorn, D., Huberman, G., \& Sengmueller, P. (2003). Herding among individual investors. Working paper, Graduate School of Business, Columbia University; New York

Gleason, K.C., Mathur, I. \& Peterson, M.A. (2004). Analysis of intraday herding behavior among the sector ETFs. Journal of Empirical Finance, 11, 681-94.

Grinblatt, M., Titman, S., \& Wermers, R. (1995). Momentum investment strategies, portfolio performance and herding: A study of mutual fund behavior. American Economic Review, 85, 1088-105.

Hwang, S., \& Salmon, M. (2004). Market stress and herding. Journal of Empirical Finance, 11(4), 585-616.

Henker, J., Henker, T., \& Mitsios, A. (2006). Do investors herd intraday in Australian equities? International Journal of Managerial Finance, 2(3), 196-219.

Holmes, P., Kallinterakis, V., \& Ferreira, M. P. L. (2011). Herding in a concentrated market: a question of intent. European Financial Management, 19(3), 497-520.

Javaira, Z., \& Hassan, A. (2015). An examination of herding behavior in Pakistani stock market. International Journal of Emerging Markets, 10(3), $474-490$.

Javed, T., Zafar, N., \& Hafeez, B. (2013). Herding behavior in Karachi Stock Exchange. International Journal of Management Sciences and Business Research, 2(2), 19-28.

Kremer, S., \& Nautz, D. (2013). Short-term herding of institutional traders: New evidence from the German market. European Financial Management, 19(4), 730-746.

Kallinterakis, V. (2009). Herding and the thin trading bias in a start-up market: Evidence from Vietnam. The IUP Journal of Behavioral Finance, VI(2), 7-27.

Kallinterakis, V., \& Kratunova, T. (2007). Does thin trading impact upon the measurement of herding? Evidence from Bulgaria. Ekonomia, 10(1), 42-65. 
Liao, T. L., Huang, C. J. \& Wu, C. Y. (2011). Do fund managers herd to counter investor sentiment? Journal of Business Research, 64(12), 207-222.

Li, D.D., \& Yung, K. (2004). Institutional herding in the ADR market. Review of Quantitative Finance and Accounting, 23, 5-17.

Lo, W.W., \& Mackinlay, A.C. (1990). When are contrarian profits due to stock market overreaction? The Review of Financial Studies, 3(2), 175-205.

Miller, M.H., Muthuswamy, J. \& Whaley, R.E. (1994). Mean reversion of Standard and Poor 500 index basis changes: Arbitrage-induced or statistical illusion?, The Journal of Finance, 49, 479-513.

Natividad, B., Pilar, C., \& Sandra, F. (2011). Detecting intentional herding: What lies beneath intraday data in the Spanish stock market? working paper, Department of Accounting and Finance, University of Zaragoza, Spain

Nofsinger, J., \& Sias, R. (1999). Herding and feedback trading by institutional and individual investors. The Journal of Finance, 54 (6), 2263- 2295.

Newey, W., \& West, K. (1987). A simple, positive semi-definite, heteroscedasticity and autocorrelation consistent covariance matrix. Econometrica 55, 703-708.

Roll, R. (1992). A mean variance analysis of tracking error. The Journal of Portfolio Management, 18(4), 13-22.

Scharfstein, D.S., \& Stein, J.C. (1990). Herd behavior and investment. American Economic Review, 80, 465-479.

Shyu, J., \& Sun, H.M. (2010). Do institutional investors herd in emerging markets? Evidence from the Taiwan stock market. Asian Journal of Finance $\mathcal{E}$ Accounting, 2(1), 125-144.

Shah, M.U., Shah, A., \& Khan, S.U. (2017). Herding behavior in the Pakistan stock exchange: Some new insights. Research in International Business and Finance, 42, 865-873

Tayde, M., \& Rao, S.V.D.N. (2011). Do foreign institutional investors (FIIs) exhibit herding and positive feedback trading in Indian stock markets? International Finance Review, 12, 169-185 
Voronkova S., \& Bohl, M.T. (2005). Institutional traders' behavior in an emerging stock market: Empirical evidence on Polish pension fund investors. Journal of Business, Finance and Accounting, 32(7), 1537-1560.

Wang, D. (2008). Herd Behavior towards the market Index: Evidence from 21 financial markets. IESE Business School Working Paper No. 776.

Walter, A. \& Weber, F.M. (2006). Herding in the German mutual fund industry. European Financial Management, 12(3), 375-406.

Welch, I. (1992). Sequential sales, learning, and cascades. The Journal of Finance, 54, 695-732.

Wermers, R. (1999). Mutual fund herding and the impact on stock prices. The Journal of Finance, 54, 581-622.

Yousaf, I., Ali, S., \& Shah, S. Z. A. (2018). Herding behavior in Ramadan and financial crises: the case of the Pakistani stock market. Financial Innovation, 4, 1-14. 